neurological sequelae. Over-ventilation in infants with HIE can lead to hypocarbia and consequent cerebral vasoconstriction further increasing the risk of brain injury. Our aim was to assess the incidence of hypocarbia in HIE and identify infants at increased risk of hypocarbia.

Methods Retrospective review of term admissions with HIE to a tertiary neonatal intensive care unit from 2008 to 2013. Hypocarbia was defined as a partial blood pressure of $\mathrm{CO}_{2}\left(\mathrm{pCO}_{2}\right) \leq$ $4 \mathrm{kPa}$.

Results 74 infants were reviewed. The median (interquartile range) gestational age was $40(38-41)$ weeks. 47 (64\%) were actively cooled. Arterial cord $\mathrm{pH}$ was 6.99 (6.80-7.10). 40 (54\%) infants had hypocarbia on day 1: $\mathrm{pCO}_{2}$ was 3.35 (2.84$3.73) \mathrm{kPa}$ and duration of hypocarbia was 160 (120-300) minutes. 48 (64.9\%) were ventilated: 11 (22.9\%) with volute targeted-ventilation, 36 (75.0\%) with non-volume-targeted ventilation and $1(1.4 \%)$ with high-frequency oscillation. Lowest $\mathrm{CO}_{2}$ was not significantly different but duration of hypocarbia was significantly longer $(\mathrm{p}<0.05)$ in infants on non-volume-targeted ventilation [200 (180-390) minutes] compared to infants on volume-targeted ventilation [120 (90-225) minutes]. On day 1, a $\mathrm{pCO}_{2}<4 \mathrm{kPa}$ was recorded in 36 of 48 infants that were mechanically ventilated (75\%), compared to 4 of 26 that were spontaneously breathing (15.4\%) [Odds ratio: 16.5, Confidence Interval: 4.73-57.76].

Conclusions Hypocarbia is frequently encountered in HIE. Mechanical ventilation of infants with HIE should aim to avoid hypocarbia by applying "neuroprotective" ventilation strategies such as volume-targeted ventilation.

\section{PO-0733 MINIMAL INVASIVE SURFACTANT THERAPY: CUI BONO?}

SM de Tollenaer, J Bierhuizen, HLM van Straaten. Neonatology, Isala Clinic, Zwolle, Netherlands

\subsection{6/archdischild-2014-307384.1373}

Background Minimal invasive surfactant therapy (MIST) is associated with a diminished need for mechanical ventilation. Insufficient insight exists in predictive success factors.

Aim Defining success factors for MIST.

Methods From 2011-2013 preterm infants admitted to the NICU with respiratory distress and radiographically established IRDS with $\mathrm{FiO} 2<0,4$ were included for MIST procedure with surfactant (Survantaâ, $100 \mathrm{mg} / \mathrm{kg}$ ) during nCPAP/nIPPV support. Therapeutic success was defined as decreased need for oxygenation without endotracheal ventilation support for $24 \mathrm{~h}$. Patient characteristics were noted; including stress, defined as clinical discomfort and/or tachycardia, as well as procedure related desaturation (minimum 80\%, <30 seconds) bradycardia and complications (tracheal injury, pneumothorax or lung haemorrhage).

Results 40 neonates (GA $24^{+2}-37^{+1}$ weeks [30 weeks], birth weight 600-3330 gram [1375 gram], IRDS grade I-III) were eligible. In 38 patients MIST was performed (2/40 were nonetheless intubated due to unrest). Tube insertion caused bradycardia with spontaneous recovery in one patient. Surfactant administration caused desaturation with spontaneous recovery in all patients and apnea in one patient. There were no complications. Therapeutic success was reached in 24/38 (63,2\%) patients. In 6/ $24(25 \%)$ respiratory adjustments were necessary; increasing PEEP in $2 / 24$, starting nIPPV in $4 / 24$. Causes for intubation $14 /$ $38(27,8 \%)$ were rebound IRDS (6/14), sepsis (5/14) and insufficient drive to breath 2/14. Gestational age, birth weight, FiO2/
IRDS degree, timing of MIST and gastric tube route (nasal/oral) were not correlated with success.

Conclusion Success factors for MIST are a calm patient, an adequate drive to breathe and the absence of sepsis.

\section{PO-0734 EFFECT OF VOLUME-TARGETED VENTILATION IN EXTREMELY LOW BIRTHWEIGHT INFANTS UNDER HIGH FREQUENCY OSCILLATORY VENTILATION}

M Enomoto, S Kikuchi, Y Katayama, A Takei, H Ikegami, H Minami. Pediatrics and Neonatology, Takatsuki General Hospital, Takatsuki, Japan

\subsection{6/archdischild-2014-307384.1374}

Background and aims Volume-targeted ventilation, or volume guarantee (VG) is known to improve neonatal prognosis in preterm infants, when added to conventional ventilation. Yet, VG effect is unclear when combined with pressure-controlled high frequency oscillatory ventilation (HFOV). The aim of this study is to investigate the effect of VG mode added to HFOV on respiratory parameters.

Methods We conducted a prospective study in extremely low birthweight infants who were ventilated after 28 days of age with HFOV (Babylog VN500). VG was applied for $8 \mathrm{~h}$ and VG was removed for the following $8 \mathrm{~h}$. Frequency $(12 \mathrm{~Hz})$ and mean airway pressure were fixed during study period in each case. Tidal volume, amplitude, minute volume (MV), heart rate $(\mathrm{HR})$ and oxygen saturation $\left(\mathrm{SpO}_{2}\right)$ data were analysed.

Results Six neonates were included (gestational age 22 w 5 d-23 w 6 d, birthweight 424-584 g). Standard deviations of both $\mathrm{SpO}_{2}$ and $\mathrm{MV}$ with VG were significantly smaller than those without VG (Figure, pared t-test). HR fluctuation was not different. In total, desaturation episodes $\left(\mathrm{SpO}_{2}\right)$.

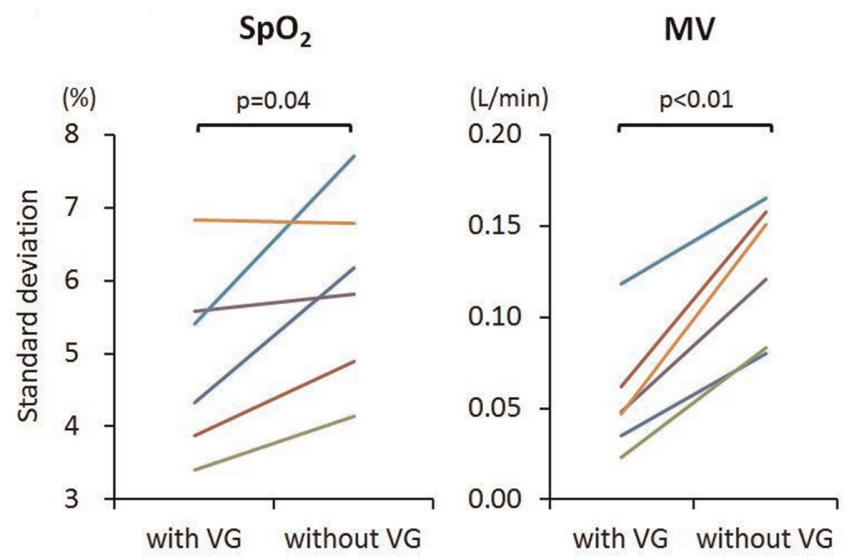

Abstract P0-0734 Figure 1

\begin{tabular}{llll}
\multicolumn{2}{c}{ Abstract P0-0734 Table 1 } & \multicolumn{2}{c}{ Comparison of desaturation episodes } \\
\hline Case & with VG & without VG & $\mathbf{p}$ \\
\hline 1 & $10.1 \%$ & $27.5 \%$ & $<0.0001$ \\
2 & $1.3 \%$ & $5.5 \%$ & $<0.0001$ \\
3 & $0.5 \%$ & $2.3 \%$ & $<0.001$ \\
4 & $9.4 \%$ & $8.6 \%$ & 0.6 \\
5 & $10.1 \%$ & $9.1 \%$ & 0.5 \\
6 & $13.6 \%$ & $13.3 \%$ & 0.8 \\
Total & $7.4 \%$ & $11.2 \%$ & $<0.0001$ \\
\hline
\end{tabular}

